\title{
REM sleep deprivation impairs serial reversal and probability maximizing in rats
}

\author{
CHESTER A. PEARLMAN, JR. and MICHAEL BECKER \\ Boston V. S. Hospital, Boston, Massachusetts 02115
}

\begin{abstract}
Deprivation of REM sleep (REMD) for about $3 \mathrm{~h}$ immediately after training greatly impaired serial spatial reversal and spatial-probability maximizing. REMD beginning $3 \mathrm{~h}$ after training had no effect. These results are consistent with the fact that these tasks clearly distinguish the learning ability of species with REM sleep (mammals, birds) from those without REM sleep (fish). The results suggest that the greater flexibility of mammalian behavior compared to that of lower species involves a REM-sleep information-processing mechanism.
\end{abstract}

Of the many hypotheses about the function of REM sleep, none has yet gained general acceptance. The weight of evidence, however, favors an information-processing theory (Hennevin \& Leconte, 1971). We have suggested that the CNS activation associated with REM sleep is involved in consolidation or assimilation of some aspects of waking experience. This idea arose from studies showing that deprivation of REM sleep (REMD) impaired adaptation to such experience in both man and rats (Greenberg \& Pearlman, in press). The prepared-unprepared learning continuum proposed by Seligman (1970) has provided operational precision for our rather vague notion of adaptation. Prepared learning occurs quickly and involves little change in the animal's behavioral repertoire, whereas unprepared learning takes longer, requires adaptive change in behavioral strategy and thus, might involve a REM sleep information-processing mechanism. For example, learning of a position habit in a Y-maze required 2-3 sessions (prepared learning) whereas comparable mastery of a brightness discrimination required 12 sessions (unprepared learning). The position habit was unaffected by brief posttrial REMD whereas the brightness discrimination was greatly impaired (Pearlman \& Becker, 1973). Similarly, one-way avoidance in rats was acquired in a few trials and was unaffected by posttrial REMD, whereas two-way avoidance required extensive training and was essentially abolished by brief posttrial REMD (Pearlman \& Greenberg, 1973; Leconte \& Hennevin, 1973).

The present study attempted to place this adaptive role of REM sleep in phyletic perspective. Bitterman (1965) showed that the greater flexibility of mammals compared to fish was clearly demonstrated by serial spatial reversal and spatial-probability tasks. Since mammals have REM sleep and fish do not, we wondered if learning of these tasks by rats required REM sleep. Such a finding would be consistent with the fact that proficiency at these tasks in various vertebrate classes (mammals $>$ birds $>$ fish) (Mackintosh, 1969) correlates with the relative prominence of REM sleep in these classes (Tauber, 1974).

We studied the effect of $3 \mathrm{~h}$ of REMD after each training session upon learning of these tasks. This duration of REMD was chosen because EEG studies of sleep following learning in rats have suggested that information processing occurs only during this period (Leconte, Hennevin, \& Bloch, 1973). Control groups which received the REMD regimen after a 3-h rest served to distinguish effects of REMD upon learning from effects on performance.

\section{METHOD}

\section{Subjects}

The Ss were 60 female hooded rats about 3 months old.

\section{Apparatus}

A conventional Y-maze, described in detail in Pearlman and Becker (1973), was used. It consisted of a startbox, choice chamber, and two goalboxes separated by hand-operated guillotine doors.

\section{Procedure}

The Ss were initially placed in the maze in groups of four for $1 / 2 \mathrm{~h} /$ day for 5 days. All doors were open, and food was available in each goalbox. During this period, the animals were reduced to about $80 \%$ of their normal weight.

For the serial spatial reversal, three groups of 10 rats were given 10 trials per day. The position of the food was shifted each day for a total of nine reversals. Training was conducted for 4 days per week. Animals were allowed about $5 \mathrm{sec}$ to eat following a correct choice and were detained in the unrewarded box for about $5 \mathrm{sec}$ after an incorrect response. Intertrial interval was about $2 \mathrm{~min}$. Following each session, one group received IP saline injection, one group had immediate REMD by IP injection of imipramine $5 \mathrm{mg} / \mathrm{kg}$ or chlordiazepoxide $4 \mathrm{mg} / \mathrm{kg}$ on alternate days, and one group received the REMD regimen after a $3-\mathrm{h}$ rest in its home cages. The alternate day drug regimen and spaced training served two purposes: (a) tachyphylaxis of the imipramine effect was avoided; (b) sufficient time elapsed between chlordiazepoxide injections to prevent accumulation of the drug (Greenblatt \& Shader, 1974).

The effect of these regimens on sleep was studied by EEG recordings of electrode-implanted animals. These rats lived in the recording chamber throughout the period of study. The recording cable was attached to the animal's head 2 days before recording began and remained connected thereafter. Except for 
24-h recordings, all data were obtained between 11:00 a.m. and 4:00 p.m., which approximated the period of REMD in animals given maze training. Two rats received the REMD regimen for 10 days, 4 days per week. On imipramine days, REM sleep onset ranged from $2.75-4 \mathrm{~h}$ following injection. On chlordiazepoxide days, REM sleep onset ranged from $3.25-4.5 \mathrm{~h}$ after injection. Non-REM sleep during the first $3 \mathrm{~h}$ after injection averaged $117 \mathrm{~min}$ for imipramine and $121 \mathrm{~min}$ for chlordiazepoxide. These results did not differ significantly from 10 uninjected control recordings (mean: 110/3 h). Twenty-four recordings were made on Days 1 and 7 (imipramine) and 2 and 8 (chlordiazepoxide) of the REMD regimen. The mean amount of REM sleep per $24 \mathrm{~h}$ (imipramine: $102 \mathrm{~min}$; chlordiazepoxide: $109 \mathrm{~min}$ ) did not differ from the mean of $104 \mathrm{~min}$ for four uninjected control recordings. Saline injection also did not affect non-REM sleep (mean of 10 recordings: $113 \mathrm{~min} / 3 \mathrm{hr}$ ) but delayed the onset of REM sleep for up to $100 \mathrm{~min}$. This delay decreased with repeated injection, and by $3 \mathrm{~h}$ after injection, the mean amount of REM sleep (11 min) did not differ from that of the uninjected control recordings $(14 \mathrm{~min})$. Thus, the REMD regimen produced $3-4 \mathrm{~h}$ of REMD with no alteration of non-REM sleep during the critical 3-h period after training while saline injection did not significantly alter the normal sleep pattern during this period.

For the probability procedure, three groups of 10 rats were given 10 trials per day during which the left side was rewarded on seven trials and the right side on three. The order of left and right placements was randomly changed each day, except that no more than three consecutive trials were rewarded on the left and two consecutive trials were never rewarded on the right. A guidance method was used. If an animal made an incorrect choice, it was immediately returned to the startbox and was given a forced run to the correct side. Otherwise, training conditions were the same as those for the serial reversal procedure. Fifteen sessions were run and, after each session, the three groups were given either (a) saline injection, (b) immediate REMD, or (c) delayed REMD as described above.

\section{RESULTS}

Table 1 shows the results for the serial reversal task. The saline and delayed REMD groups showed great improvement between initial learning and the ninth reversal. Many animals achieved errorless or single-error reversals. There was almost no overlap in performance between initial training and the final reversal (Mann-Whitney U test; $\mathrm{p}<.001$ ). In contrast, the immediate REMD animals never performed better than on initial learning and showed no significant improvement between reversals 1-9. On each of the final six reversals, there was essentially no overlap in performance between immediate REMD animals and the

Table 1

Mean Correct Responses on Serial Spatial Reversal

\begin{tabular}{|c|c|c|c|c|c|c|}
\hline & \multicolumn{2}{|c|}{ Normal Sleep } & \multicolumn{2}{|c|}{$\begin{array}{c}\text { Immediate } \\
\text { REMD }\end{array}$} & \multicolumn{2}{|c|}{$\begin{array}{l}\text { Delayed } \\
\text { REMD }\end{array}$} \\
\hline & Mean & Range & Mean & Range & Mean & Range \\
\hline Initial & 5.9 & $4-8$ & 5.8 & $4-8$ & 5.8 & $3-8$ \\
\hline Reversal 1 & 4.1 & $0-8$ & 4.5 & $1-7$ & 6.5 & $0-9$ \\
\hline Reversal 5 & 7.8 & $7-9$ & $4.8^{*}$ & $0-7$ & 7.9 & $7-9$ \\
\hline Reversal 9 & 9.1 & $8-10$ & $5.5 *$ & $2-8$ & 8.6 & $6-10$ \\
\hline
\end{tabular}

*Differs from other two groups $(p<.001)$
Table 2

Mean Choice of More Frequently Rewarded Side on 70:30 Probability Training

\begin{tabular}{|c|c|c|c|c|c|c|}
\hline \multirow[b]{2}{*}{ Day } & \multicolumn{2}{|c|}{$\begin{array}{l}\text { Normal } \\
\text { Sleep }\end{array}$} & \multicolumn{2}{|c|}{$\begin{array}{l}\text { Immediate } \\
\text { REMD }\end{array}$} & \multicolumn{2}{|c|}{$\begin{array}{l}\text { Delayed } \\
\text { REMD }\end{array}$} \\
\hline & Mean & Range & Mean & Range & Mean & Range \\
\hline 1 & 5.3 & $3-7$ & 5.5 & $2-6$ & 5.0 & $1-8$ \\
\hline 5 & 6.0 & $2-9$ & 4.8 & $2-8$ & 7.0 & $6-9$ \\
\hline 10 & 7.6 & $6-9$ & $5.6^{*}$ & $5-6$ & 8.3 & $7-10$ \\
\hline 15 & 8.9 & $8-10$ & $7.3^{*}$ & $6-8$ & 9.2 & $7-10$ \\
\hline
\end{tabular}

*Differs from other two groups $(p<.001)$

other two groups (U test: $\mathrm{p}<.001$ ).

Results for the probability procedure are shown in Table 2. The saline and delayed REMD groups showed the conventional maximization of choice of the more frequently rewarded (left) side (Bitterman, 1965). In contrast, the immediate REMD animals showed much less preference for the more rewarded side; their performance failed even to match the reward ratio until the final 2 days. For each of the last 6 days of training, there was almost no overlap in performance between the immediate REMD group and the other two groups (U test: $\mathrm{p}<.001$ ).

The matching behavior of the immediate REMD animals on the final 2 days was fairly consistent within the entire group. No rat made less than six or more than eight left choices. They showed some tendency to choose the rewarded position of the preceding trial, but this choice pattern did not differ significantly from the random matching behavior of fish in this situation (Behrend \& Bitterman, 1961). One-sample runs tests assessing reward following for each animal on these days showed no deviation from randomness at the .05 level. The randomness of this pattern was also checked by a 2 by 2 table in which left and right choices were compared with whether the preceding choice had been rewarded or nonrewarded. Chi square for these contingencies did not approach significance, thus indicating that position choice was not significantly influenced by reward of the preceding choice.

\section{DISCUSSION}

Immediate posttrial REMD was found to prevent improvement at spatial reversal and to impair spatial-probability maximizing. Thus, for these tasks, immediate REMD made rats behave like fish (Bitterman, 1965). Probability matching has been observed in rats under normal sleep conditions, though with less extensive training and clearer evidence of nonrandom response patterns than in the present study (Warren, 1965; Mackintosh, 1969). With more training, our immediate REMD group might eventually have maximized but the REMD-induced impairment was obvious. 
Skepticism about the information-processing function of REM sleep has frequently prompted the conjecture that REMD-induced learning impairment was due to some unrelated factor, such as stress or a nonspecific drug effect. The notion that REMD might impair perceptual or motivational rather than learning mechanisms has also been expressed. The brief duration of REMD and the absence of impairment with delayed REMD are difficult to reconcile with these speculations. A shared, nonspecific effect of the drugs that could impair retention immediately after training but not $3 \mathrm{~h}$ later is difficult to conceptualize. While time-dependent retention impairment of one-way avoidance is produced by more disruptive agents like ECS (McGaugh, 1966), our dosages of imipramine and chlordiazepoxide have no effect on this task. The possibility that REMD might produce a time-dependent aversion to the food reward was discussed in an earlier paper (Pearlman \& Becker, 1973). No evidence for this was noted in the present study. Furthermore, we recently investigated the effect of imipramine and chlordiazepoxide injection following exposure to a novel flavor and found no evidence of conditioned taste aversion due to these drugs.

Explanation of the learning impairment by some specific action of imipramine and chlordiazepoxide unrelated to REMD is similarly difficult. Besides REM sleep suppression, these drugs have little in common. Review of these disparate effects (Sigg, 1968; Greenblatt $\&$ Shader, 1974) does not suggest any likely alternative to REMD as a hypothetical mechanism. Finally, in two previous studies, the retention impairment due to posttrial injection of these drugs was identical to the effect of a similar period of REMD produced by the pedestal method, which involves no drugs (Pearlman \& Greenberg, 1973; Pearlman \& Becker, 1973). A CNS perturbation capable of disrupting learning which could result from such different treatments and which is distinguishable from REMD, seems inconceivable at present. Thus, the parsimonious conclusion is that our results indicated retention impairment by immediate REMD.

For the rat, the REM sleep information-processing mechanism is apparently limited to events of the preceding few hours. Animals receiving our REMD regimen began to have REM sleep about $3-4 \mathrm{~h}$ after injection but this REM sleep did not help the immediate REMD groups. Moreover, Leconte and Hennevin (1973) showed that delay of sleep onset for $3 \mathrm{~h}$ after training prevented both acquisition of two-way avoidance and the posttraining increase in REM sleep associated with this learning.

Many learning procedures, such as spatial conditioning, simple operant conditioning and extinction, simple discriminations, and one-way avoidance, cannot be related to phyletic status because these procedures show as much intraclass variation as that between classes (Warren, 1965). For the rat, the rapidity of acquisition of these tasks would classify them as prepared learning by Seligman's criteria. Previous studies have confirmed that retention does not require posttrial REM sleep (Pearlman, 1971; Pearlman, 1973; Pearlman \& Greenberg, 1973; Pearlman \& Becker, 1973). On the other hand, serial reversal and probability learning, for which the rat is relatively unprepared, reliably distinguish between phyletic classes (Bitterman, 1965). Thus, the present results further highlight the REM-dependence of unprepared learning and support Bitterman's suggestion that these tasks indicate a qualitative difference in flexibility of behavior between mammals and fish.

The finer mechanisms of serial reversal and probability maximizing remain obscure. Bitterman has related his concept of behavioral flexibility to the evolution of the cerebral cortex but Mackintosh (1969) has pointed out that this invocation of a generalized learning ability leaves much unexplained. For instance, these tasks involve contradictory learning strategies (win-stay, lose-shift for reversal and win-stay, lose-stay for probability) but training at serial reversal facilitates rather than interferes with subsequent probability training. As a possible reconciliation of these views, we would suggest that, during REM sleep, an interaction occurs between traces of waking experience and internal set analogous to the process of assimilation described by Piaget (Castle, 1971). One outcome of such interaction would be a flexible attunement (accommodation) of internal set to environmental conditions (attention to the relevant stimulus) resulting in the adjustment to inconstant reward which has been suggested by both Bitterman and Mackintosh to underlie success at serial reversal and probability learning.

\section{REFERENCES}

Behrend, E. R., \& Bitterman, M. E. Probability-matching in the fish. American Journal of Psychology, 1961, 74, 542-551.

Bitterman, M. E. Phyletic differences in learning. American Psychologist, 1965, 20, 396-410.

Castle, P. Contributions of Piaget to a theory of dreaming. In $\mathrm{J}$. H. Masserman (Ed.), Science and psychoanalysis. Vol XIX. Dream dynamics. New York: Grune \& Stratton, 1971. Pp. 98-112.

Greenberg, R., \& Pearlman, C. Cutting the REM nerve: An approach to the adaptive role of rem sleep. Perspectives in Biology \& Medicine, in press.

Greenblatt, D. J., \& Shader, R. I. Benzodiazepines in clinical practice. New York: Raven Press, 1974.

Hennevin, E., \& Leconte, P. La fonction du sommeil paradoxal: Faits et hypothèses. Année Psychologique, 1971, 2, 489-519.

Leconte, P., \& Hennevin, E. Caracteristiques temporelles de l'augmentation de sommeil paradoxal consécutif à l'apprentissage chez le rat. Physiology \& Behavior, 1973, 11, 677-686.

Leconte, P., Hennevin, E., \& Bloch, V. Analyse des effets d'un apprentissage et de son niveau d'acquisition sur le sommeil paradoxal consteutif. Brain $R$ esearch, 1973, 49, 367-379.

Mackintosh, N. J. Comparative studies of reversal and probability learning: R ats, birds, and fish. In R. M. Gilbert and N. S. Sutherland (Eds.), Animal discrimination learning. New York: Academic Press, 1969. Pp. 137-162.

McGaugh, J. L. Time-dependent processes in memory storage. Science, 1966, 153, 1351-1358.

Pearlman, C. Latent learning impaired by REM sleep deprivation. Psychonomic Science, 1971, 25, 135-136.

Pearlman, C. REM sleep deprivation impairs latent extinction in rats. Physiology \& Behavior, 1973, 11, 233-237. 
Pearlman, C., \& Becker, M. Brief posttrial R EM sleep deprivation impairs discrimination learning in rats. Physiological Psychology, 1973, 1, 373-376.

Pearlman, C., \& Greenberg, R. Posttrial REM sleep: A critical period for consolidation of shuttlebox avoidance. Animal Learning \& Behavior, 1973, 1, 49-51.

Seligman, M. E. P. On the generality of the laws of learning. Psychological Review, 1970, 77, 406-418.

Sigg, E. B. Tricyclic tymoleptic agents and some newer antidepressants. In D. H. Efron (Ed.), Psychopharmacology: A review of progress, 1957-1967. Washington, D. C: U.S. Governm ent Printing Office, 1968.

Tauber, E. S. The phylogeny of sleep. In E. D. Weitzman (Ed.) Advances in sleep research volume 1. New York: Spectrum Publications, 1974. Pp. 133-172.

Warren, J. M. The comparative psychology of learning. Annual R eview of Psychology, 1965, 16, 95-118.

(R eceived for publication May 9, 1974; revision received July 23,1974 .) 